\title{
Mobilising the
} Movement: Australian Red Cross, migration, and the role of the Red Cross and Red Crescent Movement around humanitarian response

\author{
Vicki Mau \\ Vicki Mau is the National Manager of Migration Programmes \\ at Australian Red Cross. Her teams support migrants in \\ vulnerable situations both directly and through sector \\ partnerships, community engagement and government \\ advocacy. She is Co-Chair of the Red Cross and Red Crescent \\ Asia-Pacific Migration Network.
}

\section{Abstract}

Established in war, embedded in communities and operational in every major natural and man-made disaster, the International Red Cross and Red Crescent Movement (the Movement) - including 191 National Societies - is uniquely positioned to address the humanitarian needs of migrants at all points of their journey. With migration on the rise and an area of intense debate, this article examines the work of Australian Red Cross and the collective efforts of the International Federation of Red Cross Red and Red Crescent Societies, the International Committee of the Red Cross and the Asia Pacific Migration Network, particularly across 2015-17, to support the Movement in the region in providing assistance and protection to those who are most vulnerable. It considers the progress made so far, and the potential of the Movement to engage more effectively and collaboratively on opportunities and challenges into the future. 
Keywords: migration, migrants, networks, refugees, people seeking asylum, collaboration, labour exploitation, human trafficking, immigration detention.

As a National Society, this meeting is very important on migration, to improve our knowledge, and better advocate to authorities for migrants using the principle of humanity.

APMN Migration Focal Point response after the "Mobilising the Movement" meeting, 28 April $2016^{1}$

APMN has played an important role to keep migration on the radar. There was previously not a role or focus from IFRC. APMN has been crucial in progressing this for the region.

IFRC Asia-Pacific after the 2017 APMN General Meeting, 8 June $2017^{2}$

Established in war, embedded in community, and operational in every major natural and man-made disaster, the International Red Cross and Red Crescent Movement (the Movement) ${ }^{3}$ is uniquely positioned to address the humanitarian needs of migrants at all points of their journey.

National Red Cross and Red Crescent Societies (National Societies) are present in 191 countries, with a broad reach into communities through their branches and volunteer networks. They provide humanitarian assistance to migrants in countries of origin, transit, destination and return; their emblems are universally regarded as a sign of safety.

The challenge is whether the Movement is working to its full potential for the benefit of migrants in transition, wherever they may be, and what more can be done. This challenge led Australian Red Cross to embed, in its 2020 strategy, support for a coordinated, collaborative global and regional response to the needs of migrants.

This article sets out a rationale for a coordinated Movement response to migration, details the formation and challenges faced by the Asia Pacific Migration Network (APMN), and offers evidence-based recommendations for stronger collaboration across the Movement.

1 Asia Pacific Migration Network (APMN) Secretariat, Mobilising the Movement: Humanitarian Responses to Migration in the Asia Pacific, report, Melbourne, 21 July 2016.

2 APMN Secretariat, APMN General Meeting, report, Melbourne, 30 June 2017.

3 The Movement is comprised of the International Committee of the Red Cross (ICRC), National Red Cross and Red Crescent Societies (National Societies), and the International Federation of Red Cross and Red Crescent Societies (IFRC). 


\section{The Australian Red Cross response}

For more than twenty-five years, Australian Red Cross has worked with "migrants in transition", 4 including people who have endured war, fled from conflict or experienced persecution. Its programmes support people who have been trafficked or forced into marriage against their will; people who have been separated from their loved ones because of conflict, disaster or migration; and people who might not have other support or access to mainstream services, including those who are destitute, held in immigration detention or facing deep social exclusion.

Australian Red Cross provides humanitarian support regardless of nationality, ethnicity, religion, visa status or how people arrive in Australia. Many of the people and communities with whom Australian Red Cross works have experienced significant hardship and have uncertain futures. Assistance is provided through direct services, and facilitated by support, partnerships and referrals. Systemic issues are addressed with a strong evidence base, which supports direct engagement with the authorities and policy-makers. In addition, Australian Red Cross advocates for societal change by fostering stronger understanding between communities and promoting acceptance, participation and contribution.

In Australia, where almost half of the population is born overseas or has a parent born overseas, the contribution of migrants is profound and continues to shape an open, diverse and vibrant society. However, migrants in transition largely those with unresolved or temporary visa status - remain among the most vulnerable groups in Australia. Relative to local populations, migrants typically face uncertainty surrounding legal status and the fates of loved ones, which compounds practical obstacles such as language barriers, access to support and relevant services (such as health or legal services), and barriers to participation in both education and work. Isolation can compound existing vulnerabilities such as significant trauma, experiences of deep poverty, conflict, persecution, and physical or sexual violence. For those forcibly displaced, there are often acute and immediate protection and assistance needs.

In addition, there is a noticeable trend toward increasingly negative public portrayals of migrants, impacting their ability to feel safe, to feel like they belong, and to build networks of support and assistance in the community. This can further impact on the ability of newly arrived migrants to engage with, participate in and contribute to the broader community.

\section{Australian Red Cross's connection with the Movement}

Australian Red Cross's domestic migration programmes have always engaged closely on migration policy matters with the International Federation of Red Cross and Red Crescent Societies (IFRC) and the International Committee of the Red Cross (ICRC).

4 For detailed information on Australian Red Cross migration programmes, see Australian Red Cross, "Help for Migrants in Transition", available at: www.redcross.org.au/migration-support.aspx (all internet references were accessed in November 2017). 
In 2013, Australian Red Cross started to work more intensively on regional migration matters: engaging with the ICRC to support immigration detention monitoring visits in Papua New Guinea and Nauru, agreeing to co-chair the fledgling APMN, working with the IFRC Secretariat to address policy settings within the Movement on migration, deploying delegates on migration-related missions, and integrating migration more closely within its own international humanitarian and development programming.

Australian Red Cross firmly believes that the Movement can have a greater impact on migration issues: one of the key outcomes in its Strategy 2020 is to contribute directly to this impact. Hence its policy and advocacy work looks to increase the Movement's commitment to migration work; the focus on migration at Statutory Meetings; ${ }^{5}$ the development of global strategies, advocacy and communications on migration through initiatives such as the IFRC's Global Migration Taskforce; ${ }^{6}$ and capacity development to enhance the work and voices of National Societies through domestic and regional mechanisms.

Australian Red Cross focuses on coordination and collaboration within the Asia-Pacific region. This includes global and bilateral engagement on migration issues, ${ }^{7}$ learning from and building the capacity of National Societies in areas such as protection, gender and inclusion, and working with the Australian government to inform global and regional policy, operational and coordination frameworks.

\section{Collaboration in action: Australian Red Cross and the Asia Pacific Migration Network}

Australian Red Cross is currently co-chair of the APMN, a network of National Societies in the region. ${ }^{8}$ It was established by seventeen National Societies in

5 The Red Cross and Red Crescent Statutory Meetings act as an opportunity for all components of the Movement to evaluate progress, discuss challenges, set goals and priorities, and agree on the policies which guide the Movement's work. Three main meetings take place during the Statutory Meetings: the General Assembly (biennial meeting of National Societies and IFRC to elect members of the Governing Board, admit new National Societies, and discuss financial reports and constitutive documents), the Council of Delegates (biennial meeting of all components of the Movement to discuss whole-ofMovement policies and ways of working) and the International Conference (quadrennial meeting of the Movement components and representatives of governments during which they make joint commitments on humanitarian action).

6 The IFRC Global Migration Taskforce evolved from a partnership meeting on the humanitarian needs of migrants organized by the IFRC and the Tunisian Red Crescent in Tunis on 17-18 September 2015. See IFRC, “'Tunis Commitment to our Shared Humanity'-Responding to the Needs of Migrants and Building their Resilience: A Pressing Humanitarian Imperative”, September 2015, available at: ifrc-media. org/interactive/wp-content/uploads/2015/10/IFRC-Tunis_Commitment-EN-LR.pdf. The Taskforce is a group of National Societies more actively involved in migration programmes that provide advice to the IFRC on matters of migration policy in the global, regional, national and local contexts.

7 For example, Australian Red Cross staff have been sent to National Societies for capacity-building, and delegates have been deployed to respond to emerging humanitarian crises involving migrants in locations such as Vanuatu, Fiji, Budapest, Greece, Tanzania and South Sudan.

8 New Zealand Red Cross and Mongolian Red Cross were the inaugural co-chairs in 2012-13. In 2013-17, Australian Red Cross co-chaired the network with Mongolian Red Cross Society, while currently it does so with Maldivian Red Crescent. 
Bangkok in December 2012, with the aim of exploring critical migration issues, developing actions, and contributing to a growing body of knowledge for the benefit of migrants. The ICRC and IFRC in the region have been critical supporters of the network.

The number of international migrants located in the Asia-Pacific region stands at more than 60 million, ${ }^{9}$ and $40 \%$ of the world's international migrants originate from this region. ${ }^{10}$ Asia-Pacific is home to 6.5 million refugees, or people in a refugee-like situation, 2.5 million of which are within the APMN's scope. ${ }^{11}$ Displacement and migration at this magnitude often connotes situations of extreme hardship, such as the impacts of natural disasters, conflict and violence, persecution, or untenable personal circumstances and economic hardship. It also reflects resilience and a search for opportunities around economic participation.

The Movement has a strong presence in the Asia-Pacific region throughout countries of origin, transit, destination and return. Given its mandate on humanitarian assistance and protection and, in particular, the status of National Societies as auxiliary to the authorities on humanitarian issues, there is a key role for the Movement to work with public authorities in order to better respond to the many needs and challenges that arise for migrants in this region. The APMN supports this vital work by providing a platform for National Societies to collaborate and coordinate, share knowledge and resources, build on an evidence base, and take practical action for the benefit of migrants.

Currently, the network is engaging with thirty-five of the thirty-eight National Societies in the Asia-Pacific region, as well as the ICRC and the IFRC, and has increased its engagement through regular Skype calls and teleconferences, membership updates, research and mapping, hosting events, and developing regional and thematic working groups.

\section{Research and mapping}

When the APMN was founded, ${ }^{12}$ it became evident that there was a lack of information about migration in the region, the vulnerabilities of migrants in each context, and the migration-related services and activities currently undertaken by National Societies. As such, the core work of the APMN Secretariat has been to lead research on these issues as foundational information for the Movement.

The first APMN study in September 2015 consisted of a literature review of desk research on migration issues within the region, along with a survey of

9 United Nations Economic and Social Commission for Asia and the Pacific, Towards Safe, Orderly and Regular Migration in the Asia-Pacific Region: Challenges and Opportunities, Bangkok, 2017, p. 5, available at: www.unescap.org/publications/towards-safe-orderly-and-regular-migration-asia-pacificregion.

10 Ibid.

11 Ibid., p. 25. The figure of 6.5 million includes 4 million refugees in Turkey and the Islamic Republic of Iran, which are outside of the APMN's regional scope.

12 The APMN was founded in 2012 in Bangkok at a meeting of regional National Societies and the IFRC Regional Office. 
National Societies in the region, to which twenty-six of the thirty-eight National Societies responded. The study clarified that the Asia-Pacific region has one of the highest numbers of vulnerable migrants in the world. It confirmed migration as an emerging priority for Asia-Pacific National Societies, with migrant workers being the most commonly identified group of concern. The study highlighted significant barriers to developing programmes for migrants. These barriers include lack of available resources, lack of awareness of migration issues, barriers to accessing information and the politically sensitive nature of migration issues in many countries.

The next step was to map National Society activities that support or assist migrants or persons made vulnerable through migration. The aim was to share knowledge, identify collective priorities and provide an evidence base for future work.

The report mapping National Society migration-related activities in the Asia-Pacific region ${ }^{13}$ involved consultations with National Society migration focal points to determine actions taken by National Societies to support migrants in countries of origin, transit and destination. The report highlights the valuable work undertaken by National Societies in the Asia-Pacific region and marked an opportunity for the Movement to reflect on how to better support and assist migrants - both in detention and in communities - and increase its influence on public authorities in order to address the needs and vulnerabilities of migrants in the region.

Strong cooperation and collaboration - between National Societies, the IFRC and ICRC, with authorities, and with local and international organizations was identified as a key requirement to ensure that people made vulnerable as a result of migration have access to humanitarian assistance and protection.

Contact with migrants was identified as essential to ensuring that protection and humanitarian assistance are made available to migrants, irrespective of their legal status. As such, access to detention centres and community outreach services were important components of this work.

Ensuring that migrants have access to humanitarian assistance and protection was a priority for National Societies. Health and well-being support, settlement and employment support, and emergency relief were identified as key services, in addition to supporting the humanitarian mandate to ensure the right of people to know the fates of their loved ones.

Building resilient and socially inclusive communities which promote diversity, peace and participation was highlighted as an important task for the Movement in the region. For many National Societies, this includes supporting cultural awareness activities, community education, social cohesion forums and engaging with host communities.

The regional mapping identified that in order to ensure that the Movement is best placed to respond to the needs of migrants, it is imperative to focus on collaboration, leverage existing partnerships and foster new relationships in the 
region. Most National Societies reported collaborating with external agencies as well as civil society organizations, public authorities and other Red Cross partners to support migrants in origin, transit and destination countries. Several National Societies provide pre-departure training and safe migration messaging to migrants in order to ensure that migrants can identify key risks when working overseas and in transit.

The report also highlights the work that National Societies are undertaking to assist and protect migrants: through urgent assistance such as disaster or emergency responses, and by identifying areas of concern, resources, or training opportunities that would be useful in gaining a stronger baseline understanding of migrant vulnerabilities. The mapping identified more activities than had been expected; it is important to acknowledge the breadth of migrationrelated activities under way across the region. Preparation for climate-induced migration, ${ }^{14}$ responding to the vulnerabilities of undocumented migrants and preparing nationals to go abroad for work are only some of the initiatives being delivered to ensure that migrants are educated about their rights in order to reduce vulnerabilities before they occur.

The mapping covers past and present migration-related activities and will function as a living document as the Movement adapts to emerging challenges. Of course, the politically sensitive nature of migration does limit some National Societies in engaging directly with migration-related initiatives. The APMN works to build the capacity of National Societies to understand and leverage their status as auxiliary to government, sharing approaches to advocating with public authorities on behalf of vulnerable migrants.

Several challenges were identified throughout the mapping consultations. Some National Societies were unclear on the Movement's mandate and position on migration in the region. Others highlighted difficulties in addressing issues of humanitarian concern for migrants in detention, questions regarding support for victims of trafficking, and sensitivities around supporting vulnerable groups such as people seeking asylum or people who are stateless.

As a result of this mapping, and through the recent endorsement of the IFRC Global Strategy on Migration, there is an opportunity for National Societies, the IFRC and the ICRC to consider ways in which they might develop localized strategies applicable to their local contexts, whilst collaborating with the Movement, partners, authorities and other actors to mitigate migrant vulnerabilities.

There is an ever-increasing range of opportunities for collaboration. National Societies may engage to increase the visibility of services such as restoring family links; they may improve the sharing of resources and programmatic knowledge; they may work to address any needs for increased training and resources. They can work together to better understand the

14 For example, the "Migration with Dignity" policy is part of the Pacific nation of Kiribati's long-term nationwide relocation strategy in response to climate change and related outcomes. See Office of the President of the Republic of Kiribati, "Kiribati Climate Change", available at: www.climate.gov.ki/. 
complexities of the issues that migrants face, and work more effectively with public authorities and communities.

A collaborative approach is essential to ensuring that those who are most vulnerable - no matter where they have come from - receive protection, support, assistance and connection, and are treated at all times with dignity and respect. The mapping report recommended that the IFRC, ICRC, APMN and Partner National Societies work with and through National Societies in the Asia-Pacific region to address the needs of vulnerable migrants.

This approach would also benefit Pacific National Society engagement on migration, an increasing area of concern to Pacific National Societies. The APMN, IFRC and ICRC can play an important role in ensuring that all Pacific National Societies have a baseline understanding of migration and practical, useful tools for discussing migration concerns (including how to identify vulnerabilities within local contexts and in the broader context of climate change), and are supported to include migration into organizational strategies. Further research should also be undertaken to ascertain how the Movement could best help Pacific National Societies to prepare for climate-related migration.

National Societies could benefit from tools and skills for advocating with local and national authorities for access to migrants, irrespective of their legal status. The APMN can support this through training and resources on how to undertake humanitarian diplomacy on migration. Resources should help National Societies understand and respond to particularly vulnerable migrant groups including undocumented migrants, people who have been trafficked and people moving irregularly across borders. Partnerships should explore restoring family links as means of community outreach, and develop new and creative ways to reach and connect with migrant communities.

Another key priority is to empower National Societies with tools for connecting with communities, civil society organizations, schools, workplaces and local public authorities, and for working towards more connected communities. These tools should be developed with a view to influencing a more nuanced and humanitarian understanding of Asia-Pacific migration issues in global platforms. They should facilitate engagement with the Global Compacts for Migration ${ }^{15}$ and Refugees, ${ }^{16}$ and the Global Forum on Migration and Development. ${ }^{17}$ Guidelines can be developed on how to communicate about sensitive migration issues and vulnerabilities with external partners and the authorities, in line with the Red Cross Fundamental Principles of humanity, impartiality, neutrality and independence. Recent collaboration between the IFRC, ICRC, APMN and regional National Societies on the Global Compact on Migration has been a strong example of coordinated engagement, support and impact.

15 For more information on the Global Compact for Safe, Orderly and Regular Migration, see: refugeesmigrants.un.org/migration-compact.

16 For more information on the Global Compact on Refugees, see: refugeesmigrants.un.org/refugeescompact.

17 For more information on the Global Forum on Migration and Development, see: gfmd.org/. 
The APMN and other Movement partners should also help National Societies to increase their capacity in responding to migration. This could include peer-to-peer engagement between National Societies, so they can share plans and programming and engage together on issues of concern. It could lead to National Societies providing risk-mitigating pre-departure advice to nationals within their own countries before they embark on international migration, and extending National Societies' humanitarian services beyond the limits of their State's borders. It could also entail training and tools for identifying and addressing specific vulnerabilities of migrants, such as people who have been trafficked, people who are stateless or seeking asylum, and vulnerable groups including women and children.

National Society leaders need to be aware of the Movement's mandate to protect and assist all vulnerable populations, with a focus on capacity-building for current migration activities based on the Fundamental Principles, ${ }^{18}$ the IFRC's Resolution 3 on Migration ${ }^{19}$ and Migration Policy, ${ }^{20}$ and the IFRC global and regional Strategies on Migration..$^{21}$ Support in areas such as communication, translation and technology would help to ensure that language is not a barrier for migrants seeking access to services, information or humanitarian assistance in times of need.

Building on the activities mapping, the APMN is currently undertaking a country-by-country mapping of migration issues and vulnerabilities.

\section{Events and peer learning}

Aiming to engage National Societies in supporting vulnerable migrants across the region, the APMN, ICRC and IFRC organized the first regional coordinated Movement migration event, entitled "Mobilising the Movement: Humanitarian Responses to Migration in the Asia Pacific 2016". The event promoted the unique role and mandate of the Movement in supporting vulnerable migrants. "Mobilising the Movement" was attended by secretaries-general and migration focal points from eighteen National Societies, ${ }^{22}$ as well as ICRC and IFRC colleagues from the Asia-Pacific region.

18 Humanity, impartiality, neutrality, independence, voluntary service, unity and universality: these seven Fundamental Principles provide an ethical, operational and institutional framework to the work of the Movement. They are at the core of its approach to helping people in need during armed conflict, natural disasters and other emergencies. For more information, see ICRC, "Fundamental Principles", available at: www.icrc.org/en/fundamental-principles.

19 31st International Conference of the Red Cross and Red Crescent, "Resolution 3: Migration", Geneva, 28 November-1 December 2011, available at: www.icrc.org/eng/resources/documents/resolution/31international-conference-resolution-3-2011.htm

20 IFRC, "Policy on Migration", November 2009, available at: media.ifrc.org/ifrc/wp-content/uploads/sites/ 5/2017/03/Migration-Policy_EN.pdf

21 IFRC, IFRC Global Strategy on Migration 2018-2022: Reducing Vulnerability, Enhancing Resilience, Geneva, 2017, available at: media.ifrc.org/ifrc/wp-content/uploads/sites/5/2017/12/IFRC_StrategyOnMigration_EN_ 20171222.pdf.

22 The National Society attendees included representatives from Afghanistan, Australia, Bangladesh, Fiji, Indonesia, Kiribati, Malaysia, Mongolia, Myanmar, Nepal, New Zealand, Pakistan, Philippines, the Solomon Islands, Sri Lanka, Timor Leste, Tonga, Tuvalu and Vanuatu. 
In May 2017, as co-chair and Secretariat of the APMN, Australian Red Cross organized the first APMN peer-to-peer learning between Asia-Pacific National Societies. Colleagues from the Pakistan Red Crescent, Sri Lankan Red Cross and Bangladeshi Red Crescent joined Australian Red Cross staff to discuss migration issues, challenges and opportunities around restoring family links, labour migration and exploitation, detention of migrants, supporting asylumseekers in the community, preparedness, responding during a disaster, and safe migration. The peer learning highlighted that although National Societies work in different contexts or along different stages of the migration journey, they share a common objective: to support people made vulnerable through migration, at any stage of their journey. Participants reported the effect on interpersonal working relationships, noting that it is easier to have open discussions on sensitive, complex topics with people who one has spent time with in person. National Society focal points have expressed interest in engaging in additional peer learning opportunities, both as hosts or participants - an important outcome of the process. In 2018, Australian Red Cross is welcoming another five National Societies' representatives to engage in peer learning.

The 2017 APMN Annual General Meeting (AGM) took place on Thursday, 8 June following the IFRC Migration and Health meeting in Kuala Lumpur, Malaysia. Twenty-two participants from fourteen Asia-Pacific National Societies were present for the AGM, including two secretaries-general and one deputy secretary-general, as well as IFRC and ICRC representatives. Participants discussed the importance of building on approaches to engage community leaders, civil societies and public authorities on migration, through region-focused leaders' forums in South Asia, Southeast Asia and the Pacific. The meeting saw the Maldivian Red Crescent take on the co-chair role of the APMN with Australian Red Cross, which will continue to provide Secretariat support.

Four thematic and regional working groups - with ongoing ICRC and IFRC technical expertise and support-were reviewed and developed at the meeting. These groups are: migration in the Pacific; labour migration and understanding the needs of people who have been trafficked; collaboration on migration in South Asia; and migration and health. Key working group outcomes thus far include the endorsement of the Pacific Statement on Migration developed by the APMN Pacific Working Group and circulated at the Pacific Leaders forum. Participants at the AGM agreed to build on this model as way to engage leaders on migration.

The APMN prioritizes engagement with other networks within and beyond the region, including the Platform for European Red Cross Cooperation on Refugees, Asylum Seekers and Migrants (PERCO), the Asian Red Cross and Red Crescent AIDS Task Force, and the European Red Cross Action for Trafficked Persons Network. On 16 October 2016, the second meeting of Movement regional networks was held with the APMN and PERCO. This meeting explored lessons learned, information sharing and ways to extend practical collaboration. The network also conducts regional consultations with Asia Pacific National Societies, most recently on the IFRC Global Migration Strategy and Global 
Communication Strategy and on the IFRC's response to the Global Compact on Refugees and the Global Compact on Safe, Orderly and Regular Migration. ${ }^{23}$ APMN members are kept up to date and engaged with the network through regular communications, Skype calls, emails and sharing of information on migration.

\section{National Societies' voices}

The APMN began surveying Asia-Pacific National Society focal points in 2015 and observed many attitudinal and programmatic changes over the subsequent two-year timeframe. The results from the 2017 survey (to which thirty of thirty-eight National Societies responded) showed a marked increase in organizational documents that included reference to migration relative to the 2015 results.

Focal points were asked to indicate their views on which migration-related issues were a priority for their National Society. There were positive developments in this space, with many expressing increasing knowledge of, and concern toward, migrants in their communities.

Aside from political obstacles, barriers identified by National Societies to working with or prioritizing migrants within their organizations were predominantly related to a lack of support and collaborative measures. In this regard, some National Societies highlighted the following when asked about barriers to supporting migrants:

"Other [organizations] including our government are yet to prioritise migration in their plans."

"[There is a] lack of knowledge on migration activities; for example, how to develop the assessment tools, identification of needs and further steps."

"[Lack of] cooperation with National Societies, specifically from the receiving countries for labour migrant workers in the Middle East."24

When asked about the most useful aspect of their engagement with the Network, APMN focal points cited meetings, peer-to-peer learning, migration events (such as "Mobilising the Movement"), receiving key updates from regional migration events, and participating in working groups.

National Societies now look to the APMN as a platform to assist in capacity-building, peer learning and increasing their knowledge on activities and opportunities that address the humanitarian needs of migrants. The APMN will work closely with Movement partners to progress these areas of requested support.

23 IFRC, "IFRC Policy Brief: Global Compact on Migration”, Geneva, 3 December 2017, available at: media. ifrc.org/ifrc/document/ifrc-policy-brief-global-compact-migration-2/.

24 APMN Secretariat, above note 2. 


\section{Call to action: Moving from understanding to action}

As co-chair of the APMN and a participant in a range of global and regional working groups, Australian Red Cross has the opportunity to move from building understanding of migrant needs to mobilizing partners in strategy, data and collective action. Australian Red Cross is proud to work as part of a Movement that responds to increasing global migration challenges, be it through the Migration and Refugee Compacts, the Global Forum on Migration and Development, or the development of the first IFRC Global Migration Strategy.

The Movement has extraordinary capacity to offer a humanitarian response to the needs of vulnerable migrants all over the world. Collaboration, coordination and the sharing of skills and resources between all Movement actors will be critical in this response.

\section{Conclusion}

There is a growing need to ensure that the work of National Societies reflects the realities of human mobility as it exists today, such that human suffering is mitigated and migrants may more easily become assets to their destination countries. National Societies and the broader Movement have a mandate to advocate to public authorities so that addressing the humanitarian needs of migrants becomes a more focused component of national policies and planning, and so that global documents enshrine humanitarian responses as central to how States and other actors deal with the growing number of people seeking better lives overseas.

Australian Red Cross sees work with and for migrants not as a choice but as a humanitarian necessity for the Movement. At a time when public opinion is divided and the issue of migration is an area of intense debate, the Fundamental Principles provide a crucial guide. Regardless of who you are, where you come from or your legal status, the Movement aims to provide assistance and protection to those who are most vulnerable.

If the Movement can draw effectively on its presence across 191 countries, its reach into and across communities through 13 million volunteers, and its influence and role with government, it can not only provide assistance and protection but also coordinate across borders to ensure that no one in need is left without support, as well as influencing the global and national agenda to ensure that humanity is at the core of any response.

Most of all, the Movement must work alongside and support communities themselves to determine their needs and utilize their strengths, always recognizing the resilience and capacity of migrants. Movement actors should leverage the trust they enjoy within their own countries to build more cohesive, supportive and inclusive communities. 